\title{
COMPLIANCE E LEI ANTICORRUPÇÃO
}

\author{
COMPLIANCE AND ANTI-CORRUPTION LAW
}

\author{
Emerson Ademir Borges de Oliveira ${ }^{1}$ \\ UNIVERSIDADE DE MARÍLIA
}

\begin{abstract}
Resumo
O combate à corrupção não transparece nenhuma novidade no universo jurídico e político. Contudo, nas últimas décadas tem sido conduzido para frentes distintas, que tomam por base não mais um olhar sobre o Estado, e sim uma análise sobre o papel das empresas. Vale dizer, medidas que apostam na fiscalização das pessoas jurídicas para atingir formas preventivas e repressivas de combate a atos que causem dano à Administração Pública. Desde 1934, com o Securities Exchange Act há uma preocupação com a conduta das empresas, mas foi com o FCPA, em 1977, que mecanismos de controle e fiscalização foram instituídos com o intuito de bloquear atos de corrupção. Em 2002, a Lei Sarbanes-Oxley se une ao propósito para fins de evitar fraudes ao mercado. Alia-se, ainda, Convenções Internacionais de Combate à Corrupção da ONU, OEA e OCDE. Entre nós, a preocupação com a atuação das pessoas jurídicas ganha coro com a Lei Anticorrupção, de 2013, regulamentada em 2015, e vocacionada a penalizar as empresas que promovam o intuito combatido, tanto na esfera administrativa quanto judicial. Mais do que isso, e sob o aspecto preventivo, preocupa-se com a criação de programas de integridade, valendo dos mesmos para diminuição de penalidade e até mesmo para acordos de leniência. O propósito deste artigo, após o deslinde histórico, é avaliar as especificidades e importância do instrumento legal. Para a concretização da pesquisa observou-se o método dedutivo, embasado em pesquisa bibliográfica.
\end{abstract}

Palavras-chave

Compliance. Programa de integridade. Lei Anticorrupção. Combate à corrupção.

\begin{abstract}
The fight against corruption does not show any novelty in the legal and political universe. However, in the last decades it has been led to different fronts, based on no more looking at the state, but at analyzing the role of companies. That is to say, measures that bet on the supervision of the legal entities to reach preventive and repressive forms of combat to acts that cause damage to the Public Administration. Since 1934, with the Securities Exchange Act, there has been a concern about corporate conduct, but it was with the FCPA (Foreign Corrupt Practices Act) in 1977 that control and enforcement mechanisms were instituted to block acts of corruption. In 2002, the Sarbanes-Oxley Act joins its purpose in order to avoid market fraud. International Conventions to Combat Corruption of the UN, OAS and OECD are also included. Among us, the concern with the activities of legal entities is in line with the Anti-Corruption Law of 2013, regulated in 2015, and aimed at penalizing companies that promote the purpose of fighting, both in the administrative and judicial spheres. More than that, and in the preventive aspect, it is concerned with the creation of programs of integrity, using them to reduce penalties and even for leniency agreements. The purpose of this article, after the historical demarcation, is to evaluate the specificities and importance of the legal instrument. In order to carry out the research, the deductive method was observed, based on bibliographic research.
\end{abstract}

Keywords

Compliance. Integrity program. Anti-Corruption Law. Fight against corruption.

\section{INTRODUÇÃO}

O Brasil é um país signatário de Convenções Internacionais de combate à corrupção capitaneadas pela Organização das Nações Unidas, Organização dos Estados Americanos e Organização para a Cooperação e Desenvolvimento Econômico.

\footnotetext{
${ }^{1}$ Mestre e Doutor em Direito Constitucional pela Universidade de São Paulo. Pós-Doutor em Democracia e Direitos Humanos pela Faculdade de Direito da Universidade de Coimbra. Professor Assistente Doutor nos cursos de Graduação, Especialização, Mestrado e Doutorado em Direito da Universidade de Marília. Coordenador-Adjunto do Programa de Mestrado e Doutorado da Universidade de Marília. Advogado e parecerista.
} 
A postura perante a ordem internacional, bem como a influência de países que passaram a adotar leis rígidas de combate à corrupção, como os Estados Unidos e a Inglaterra, conduziram o país no inafastável caminho da prevenção e repressão aos atos corruptivos.

Em termos preventivos, com relevo nas companhias norte-americanas, as empresas passaram a adotar instrumentos que buscassem prevenir, internamente, a ocorrência de atos desviantes, o que ganhou ênfase com a Foreign Corrupt Practices Act e a Lei Sarbanes-Oxley.

Embora projeto datado de 2000, apenas em 2013 ascende no Brasil a Lei Anticorrupção Empresarial, destinada a prevenir e reprimir a prática de atos corruptivos por parte das empresas e em detrimento da Administração Pública. Além de inovar a temática por tratar de forma específica o relacionamento entre o particular e o público, a lei previu a responsabilização objetiva das pessoas jurídicas pela prática de ilícitos que envolvam obtenção de vantagens indevidas, ilícitos em licitações e obstrução de investigação, trazendo, como novidade, a aplicação de multa e o name and shame, no plano administrativo, bem como outras sanções judiciais.

Há de se destacar, no entanto, a atenção especial que a lei conferiu aos programas de integridade - compliance -, com definição e requisitos estabelecidos pelo decreto que a regulamenta. Grosso modo, são programas que buscam garantir e demonstrar a conformidade das empresas com as leis nacionais, de forma a exteriorizar confiança e credibilidade junto ao mercado.

Além de estarem permeadas por práticas exigidas em um contexto internacional - como ocorre com as empresas que negociam títulos mobiliários nos Estados Unidos e as exigências da SOX - as medidas, além de prevenir a ocorrência de ilícitos por parte dos agentes, ainda auxiliam na flexibilização de eventuais reprimendas.

É que, como será estudado com mais detalhes, a existência de programas de integridade efetivos é tomada em consideração na aplicação das penalidades, bem como influencia a possibilidade do estabelecimento de acordos de leniência.

Vê-se, assim, que mais do que o aspecto punitivo necessário e específico, haja vista a inexistência até então de uma lei que promovesse a responsabilização da pessoa jurídica pelos atos de corrupção, a legislação avança no caminho de estímulo de programas de integridade, ajustandose, assim, às tendências internacionais e às necessidades de um universo não mais complacente com a desconformidade.

Para o desenvolvimento da pesquisa observou-se a revisão bibliográfica, com amparo na doutrina e análise legislativa. Já na abordagem utilizou-se o método dedutivo.

\section{DELIMITAÇÃO DO TEMA, CONCEITO E ORIGEM}


As experiências corruptivas no Brasil e no mundo têm conduzido, de forma mais acentuada nos últimos anos, à adoção de medidas, privadas e públicas, destinadas a estabelecer formas de gerenciar os pontos mais vulneráveis de empresas e governos, controlando-se os riscos a fim de manter a integridade.

Antes de aprofundar a discussão, contudo, é preciso estabelecer uma delimitação oportuna. Como será visto, a terminologia compliance fora adotada no Brasil, inclusive legalmente, como sinônimo de "programa de integridade", a qual aderimos. Não se olvide a existência de entendimento diverso, sob a argumentação de que compliance estaria mais ligado a um estado de coisas (estar de acordo), o que conduziria à criação de um programa de integridade.

Como explicam Mendes e Carvalho (2017, p.29), compliance advém do termo to comply, isto é, cumprir, e um "programa de compliance visa estabelecer mecanismos e procedimentos que tornem o cumprimento da legislação parte da cultura corporativa". Noutras palavras, visa estabelecer um programa de integridade.

Veríssimo (2017, p.90), na mesma linha, assevera que compliance significa "concordância com o que é ordenado". E ressalta (VERÍSSIMO, 2017, p. 92-93) que a ideia de compliance se transmuda para a criação dos programas de compliance ou de integridade. Há, assim, uma acepção no sentido de que o compliance traduziria a forma de agir, apta a gerar a criação de um programa que se direcione àquelas diretrizes.

Para o trabalho, contudo, entendemos a diferenciação como despicienda, eis que ambos os termos conduzem ao mesmo objetivo: estabelecer um programa de conformidade acerca do modo legal e ético de agir. Portanto, tomaremos como sinônimos.

De acordo com o Conselho Administrativo de Defesa Econômica (2016, p.9), "Compliance é um conjunto de medidas internas que permite prevenir ou minimizar os riscos de violação às leis decorrentes de atividade praticada por um agente econômico e de qualquer um de seus sócios ou colaboradores".

Ainda, o artigo $2^{\circ}$ do Código de Compliance Corporativo da IBDEE (2017, p.11) elucida:

O Compliance é uma função indispensável nas empresas, independentemente do seu porte e do seu segmento, e visa assegurar que o exercício das suas atividades se dê de forma sustentável, em estrita conformidade com o ordenamento jurídico e as normas aplicáveis, bem como em consonância com elevados padrões éticos e responsabilidade social.

Não envolve, o compliance, apenas a obediência a certos aspectos formais da legislação, mas um conjunto mais amplo de padrões, condutas éticas, absorção cultural e empoderamento dos empregados que encabeçam as suas principais medidas. Mais do que simples medidas, o contexto 
envolve uma abordagem mais ampla que passa a direcionar a atuação da empresa como um todo. É como se, a partir de tais vertentes, a corporação passasse a ser adjetivada pela conformidade.

Os Programas de Compliance, muitas vezes alcunhados Programas de Integridade, demonstram a assunção de uma responsabilidade perante o estabelecimento de práticas cotidianas de adequação legal e gerenciamento de uma cultura de fiscalização por parte de todos os envolvidos.

A perspectiva, a propósito, possui definição legal, nos termos do artigo 41 do Decreto n. 8420/2015:

\begin{abstract}
Programa de integridade consiste, no âmbito de uma pessoa jurídica, no conjunto de mecanismos e procedimentos internos de integridade, auditoria e incentivo à denúncia de irregularidades e na aplicação efetiva de códigos de ética e de conduta, políticas e diretrizes com objetivo de detectar e sanar desvios, fraudes, irregularidades e atos ilícitos praticados contra a administração pública, nacional ou estrangeira.
\end{abstract}

Daí porque, alinhada a tal propósito, asseverar a Controladoria-Geral da União (2015, p.6), que os Programas de Integridade focam na adoção de medidas anticorrupção por parte das empresas, especialmente com o escopo de evitar danos à administração pública de um modo geral.

Gerenciar a conformidade e prevenir medidas corruptivas não revela um modelo absolutamente novo, embora, entre nós, tenha ganhado notoriedade a partir de 2015. Para Biegelman (2008, p.106-107), entre os anos 60 e 70, nos Estados Unidos, algumas condutas antitruste e concorrenciais, após trazerem impactos judiciais, estimularam algumas empresas a desenvolverem métodos de conformidade internos. Naquele momento, o público acadêmico voltou seus olhos para os atos ilícitos praticados pelas corporações e a ausência de normas internas de proteção contra tais condutas, o que certamente influenciou na deflagração de procedimentos internos de controle.

De forma mais ampla e generalizada, o surgimento das agências reguladoras nos Estados Unidos estimulou o desenvolvimento das técnicas de compliance: "O governo americano criou o programa como forma de fiscalização das instituições financeiras, mas aproximadamente em 1992 se ampliou para as atividades de saúde, comercio de alimentos e atividade ilícitas como a venda de entorpecentes" (XAVIER et alli, 2017, p.3).

Nos idos atuais, após a inserção de imprescindíveis elementos legislativos, a serem adiante mais detalhados, a questão tornou-se mais evidente e oficializada. O profissional de compliance passou a merecer denominação e treinamento específico. O Chief Compliance Officer (CCO), nesta linha, tornou-se um dos mais importantes membros das corporações, classificado como um agente que tem o intuito de promover a integridade dentro da organização (VIEIRA, 2013, p.21). 
Recomenda-se, ademais, que as empresas mantenham um Comitê de Compliance, liderado pelo Compliance Officer, bem como membros de diversos órgãos da empresa, como diretoria, departamento jurídico, financeiro, recursos humanos, dentre outros (IBDEE, 2017, p.17). A título de exemplo, a Patria/Blackstone adota o Comitê de Legal e Compliance, composto pelos seguintes membros: “(i) Sócio do Comitê Executivo responsável por Compliance, (ii) Sócio do Comitê de Gestão responsável por Compliance; (iii) Diretor de Legal e Compliance, sendo presidido pelo Diretor de Legal e Compliance" (PATRIA, 2017, p.12). Na Petrobras, em outro exemplo, há a Diretoria de Governança, Risco e Conformidade (PETROBRAS, 2015, p.13).

É certo que não existe um único modelo de Programa de Integridade. Na realidade, embora os programas sejam dotados de alguns aspectos comuns, a serem adiante delineados, é natural que o ramo de atividade exija certas especificidades. As peculiaridades de cada área, assim, devem voltar-se para os riscos que cada tipo de negócio produz.

Um dos pontos que todo programa deve ter em comum é a necessidade de comprometimento, desde a alta direção até todos aqueles que estabelecem alguma relação com a empresa, sejam empregados ou acionistas. A participação da alta direção - tone from the top desempenha papeis primordiais para o sucesso do programa, tais como o exemplo, a transmissão da importância e a inserção no atingimento das metas e da fiscalização. No mais, assume-se um compromisso com a manutenção hígida do próprio programa, desde aspectos organizacionais até recursos econômicos.

Além disso, é fundamental que os responsáveis pela execução do programa, diga-se, aqueles que o dirigem - já que a todos cabe a adequação da conformidade - devem ser dotados de autonomia nos ramos empresariais, até mesmo diante da possibilidade de circunstâncias que venham a gerar oposição com outros empregados, acionistas e até mesmo diretores. Os dirigentes de compliance precisam estar dotados de um poder que não lhes gere risco ou afronta durante as suas ações.

Ao longo de sua execução, um programa imprescinde da análise constante de riscos ${ }^{2}$. Não se trata apenas dos riscos decorrentes do comportamento interno, mas, sobretudo, das consequências da corporação no mercado, mormente diante daqueles em que há grandes concorrentes, alta concorrência ou elevados interesses econômicos. A análise de riscos, nessa linha, envolve a sujeição a determinadas situações que poderiam rasurar a integridade da companhia e, especialmente, como deve esta se portar diante de tais ocorrências.

\footnotetext{
2 "Essa avaliação deve considerar principalmente a probabilidade de ocorrência de fraudes e corrupção, inclusive ligadas a licitações e contratos, e o impacto desses atos lesivos nas operações da empresa. Com base nos riscos identificados, serão desenvolvidas as regras, políticas e procedimentos para prevenir, detectar e remediar a ocorrência dos atos indesejados" (CGU, 2015, p.10).
} 
É neste momento que entra o tratamento ou mitigação do risco, vale dizer, o treinamento destinado à reação da empresa - e de todos os seus interessados - diante de uma perspectiva de risco. Por exemplo, como deveria proceder um executivo convidado a compor um cartel para lidar com licitações e contratações públicas? Se é certo que qualquer programa de integridade mínimo rejeita a inserção em esquemas ilícitos e fraudulentos, não é certo que estejam os empregados preparados para lidar com tais desvios.

A propósito, este deve ser um jogo aberto e sincero. Daí a necessidade de confiança recíproca a ser desenvolvida pelo programa, de modo que qualquer empregado tenha a liberdade de questionar e informar sobre eventuais circunstâncias.

A cooperação, aliás, é um dos principais elementos da política de integridade. Além de permitir maior sucesso ao programa, gera relações mais estáveis e satisfeitas. Internamente, tem-se empregados mais satisfeitos; externamente, clientes e fornecedores mais seguros. Frise-se, ademais, que uma das premissas da cooperação é justamente a redução dos conflitos, o que encontra indução na consecução dos objetivos comuns do programa.

É preciso, ademais, que o Programa esteja sempre sujeito a revisões, em especial diante de novos riscos e condutas contemporâneas que possam gerar desconformidade. O Manual de Compliance da Patria/Blackstone, por exemplo, indica essa preocupação no item 5.6: “Ao menos uma vez por ano, o Compliance deverá conduzir uma revisão completa de todo Programa de Compliance, que inclui este Manual, a agenda regulatória, o programa de treinamento, as revisões de formulários e testes de aderência" (PATRIA, 2017, p.16).

De acordo com o Legal Ethics Compliance, na visão de Xavier et alli (2017, p.5-6), o compliance escora-se em oito pilares: a) suporte da alta direção; b) avaliação de riscos; c) código de conduta e políticas de compliance; d) controles internos; e) treinamento e comunicação; f) canais de denúncia; g) investigações internas; h) diligência adequada (due diligence $\left.{ }^{3}\right)$; i) auditoria e monitoramento.

Ligeiramente distinto, para a Controladoria-Geral da União (2015, p.6-7), tratam-se de cinco pilares: a) comprometimento e apoio da alta direção; b) instância responsável pelo programa de integridade; c) análise de perfil e riscos; d) estruturação das regras e instrumentos; e) estratégias de monitoramento contínuo.

Os objetivos para a realização de compliance são variados, dentre os quais podem ser listados a adequação legal, nacional e internacional, a prevenção a demandas judiciais e administrativas, transparência nos negócios, evitar conflitos de interesse, evitar a prática de ilícitos pessoais, como

\footnotetext{
${ }^{3}$ Veja-se, por exemplo, a due diligence de integridade - DDI, da Petrobras: "A DDI corresponde à avaliação do Grau de Risco de Integridade (GRI) ao qual a Petrobras pode estar exposta no relacionamento com seus fornecedores, parceiros operacionais e em contrapartes nos processos de aquisição ou desinvestimento, a partir de informações relacionadas à reputação, idoneidade e às práticas de combate à corrupção dos mesmos. Em relação aos fornecedores, tal avaliação é revisada anualmente, por ocasião da renovação do cadastro” (PETROBRAS, 2015, p.16).
} 
lavagem de dinheiro e atos de corrupção e disseminar uma conduta de integridade (RIBEIRO; DINIZ, 2015, p.89).

De acordo com o CADE (2016, p.11), um dos benefícios do compliance é a mitigação de riscos de violação legal e, consequentemente, de suas consequências, administrativas ou jurídicas, cíveis e até mesmo penais:

\begin{abstract}
No direito concorrencial, além de multa, a LDC prevê diversas outras penas em caso de infração à ordem econômica, como publicação da decisão condenatória em jornal de grande circulação, proibição de contratar com instituições financeiras oficiais e participar de licitação por até cinco anos, inscrição do infrator no Cadastro Nacional de Defesa do Consumidor, recomendação de licença compulsória de direito de propriedade intelectual de titularidade do infrator, negativa de parcelamento de tributos federais e cancelamento de incentivos fiscais ou subsídios públicos, a cisão de sociedade, transferência de controle societário, venda de ativos ou cessação parcial de atividade, e proibição de exercer o comércio em nome próprio ou como representante de pessoa jurídica por até 5 (cinco) anos (CADE, 2016, p.11-12).
\end{abstract}

É, por evidente, a adoção de tais procedimentos voltada ao alinhamento interno, ao gerar a cultura e conhecimento acerca de integridade, permitirão a célere identificação de eventuais parceiros de negócios que não coadunam com as mesmas exigências. Não só. Ao adotar um programa de integridade sério e claro - e não apenas de fachada ou sham progams -, há perspectivas quanto à imagem da empresa perante o público externo, a fim de gerar maior credibilidade ${ }^{4}$, em especial se alinhado a técnicas de governança: "Ações afirmativas de incentivo à conformidade com a lei são parte essencial de uma cultura de ética nos negócios, que resulta em benefícios para a reputação da organização e sua atratividade para fins promocionais, de recrutamento e de retenção de colaboradores" (CADE, 2016, p.13).

Por vezes, é certo que, apesar dos programas de integridade, as empresas não consigam se desvencilhar de práticas atentatórias ao mercado praticadas por membros mal intencionados. Mas, valendo-se do comprometimento de um programa, poderá buscar a celebração de eventual acordo de leniência junto ao Conselho Administrativo de Defesa Econômica: “O programa de compliance não garante que a leniência será assinada, mas ele pode aumentar substancialmente as chances de a entidade poder contar com essa ferramenta" (CADE, 2016, p.40).

Além disso, embora "um programa de compliance não ser suficiente para afastar a possibilidade de imposição de penalidades pelo Cade, em algumas situações ele pode impactar favoravelmente a determinação dessas penalidades" (CADE, 2016, p.42), uma vez que nos termos do artigo 45 da Lei do CADE, na aplicação da penalidade, o Tribunal considerará I - a gravidade

\footnotetext{
4 "Enfim, uma vez implantada tal política e funcionando de forma efetiva, a empresa tende a obter mais confiança dos investidores e maior credibilidade no mercado. Assim, alcançará altos níveis de cooperação interna e externa, com o consequente aumento de lucro, mas sempre de forma sustentável, trazendo benefícios à organização, a seus empregados e à sociedade" (RIBEIRO; DINIZ, 2015, p.90).
} 
da infração; II - a boa-fé do infrator; III - a vantagem auferida ou pretendida pelo infrator; IV - a consumação ou não da infração; V - o grau de lesão, ou perigo de lesão, à livre concorrência, à economia nacional, aos consumidores, ou a terceiros; VI - os efeitos econômicos negativos produzidos no mercado; VII - a situação econômica do infrator; e VIII - a reincidência.

Nota-se, assim, como os programas de integridade se tornaram imprescindíveis para o desenvolvimento da boa governança no interior das corporações, gerando efeitos imediatos, inclusive, na seara pública. Essencial, neste contexto, compreender como a legislação internacional e nacional propiciaram a evolução dos programas de integridade no Brasil e no mundo.

\section{FCPA E LEI SARBANES-OXLEY}

Nos anos 70, nos Estados Unidos, um escândalo desdobrado de Watergate revelou a existência de mais de quatrocentas empresas que teriam pago algum tipo de propina para a obtenção de algum tipo de favor por parte do governo federal.

Em consequência, fora editado o Foreign Corrupt Practices Act (FCPA), de 1977, primeira lei norte-americana vocacionada especificamente para o combate à corrupção quando praticada em relação a funcionários públicos estrangeiros. A lei estabeleceu sanções de natureza cível, administrativa e penal que se aplica a pessoas e empresas norte-americanas que se valem de corrupção junto ao Poder Público estrangeiro, quando atuam no exterior, para a obtenção de vantagens ilícitas. Ainda, a lei estrutura um sistema de combate à corrupção em transações comerciais internacionais.

Para garantir o sucesso de seu objetivo a lei se vale de instrumentos como a manutenção de livros e registros contábeis escriturados, bem como relatórios periódicos, sistemas de auditoria e controles internos para evitar violações. A lei ainda veda o pagamento de propinas de qualquer natureza para influenciar decisão de dirigente estrangeiro, induzi-lo a realizar ou deixar de realizar qualquer conduta contra sua obrigação legal, garantir vantagem indevida ou utilização de influência por parte de dirigente estrangeiro.

A FCPA, contudo, não é documento isolado, havendo outros, decorrentes ou não da legislação no direito comparado.

Há exemplos de estruturas de incentivo ao Compliance: decisões no âmbito administrativo e judicial, governança corporativa, Índice de Sustentabilidade Empresarial da Bovespa, Lei Sarbanes-Oxley, Índice Dow Jones, estrutura criada pela UK Bribery Act, além da modificação do Código Penal na Espanha (RIBEIRO; DINIZ, 2015, p.98). 
Ainda nos Estados Unidos, um novo escândalo financeiro no início dos anos 2000, que causara prejuízos de mais de US\$100 milhões a investidores, capitaneado sobretudo pela Enron, a partir da maquiagem de uma auditoria de fins desviados, a Arthur Andersen, levou o Congresso norte-americano a estabelecer legislação que tivesse o intuito principal de criar mecanismos seguros de auditoria e controle nas empresas que negociam suas ações no mercado, evitando-se fraudes, garantindo transparência, em especial por técnicas de governança.

$\mathrm{Na}$ ocasião, apesar das dívidas bilionárias da Enron, empresa do setor energético, a auditora Andersen auxiliou a empresa na manipulação dos balanços e ocultação das dívidas para demonstrar um lucro artificial e manter a confiança do mercado (SILVA; MACHADO, 2008, p.4).

O senador Paul Sarbanes e o deputado Michael Oxley reuniram seus propósitos na SarbanesOxley Act (Public Company Accounting Reform and Investor Protection Act), assinada em 30 de julho de 2002 pelo então Presidente George W. Bush.

De acordo com a Seção 100 da lei fica criado o Public Company Accounting Oversight BoardPCAOB, a atuar em conjunto com a Securities Exchange Comission - SEC, a qual faz as vezes de gerenciamento dos valores mobiliários. A PCAOB tem o propósito de fiscalizar o trabalho dos auditores das companhias de capital aberto (MENEZES, 2018, p.29).

Interessante objetivo é revelado pela Seção 202, que estabelece rotatividade nos serviços prestados pelos auditores independentes, inclusive no tocante à administração das próprias empresas de auditoria.

$\mathrm{Na}$ linha do compliance empresarial, a Seção 301 estabelece requisitos para instalação dos Comitês de Auditoria, de caráter independente, bem como canal de comunicação para denúncias e o fluxo da transparência de informações. Os membros do Comitês de Auditoria também devem pertencer ao Conselho de Administração e ser independentes, não percebendo qualquer outro tipo de remuneração da empresa (MENEZES, 2018, p.31) Ainda, a Seção 406 aborda o estabelecimento de um código de ética obrigatório e de revisão contínua.

Destaca-lhe a Seção 404, a qual lida com os relatórios financeiros das empresas e o papel do auditor independente ${ }^{5}$, em conjunto com a Seção 302. De acordo com a primeira, os executivos das companhias devem avalizar os sistemas de controle financeiro ${ }^{6}$. "A Seção 404 determina uma avaliação anual dos controles e procedimentos internos para a emissão de relatórios financeiros,

\footnotetext{
5 “(...) o auditor independente é responsável pelo entendimento e pelos testes de controles internos das demonstrações contábeis e pela elaboração de um parecer sobre a efetividade desses controles” (MENEZES, 2018, p.32).

6 "Cada título contemplado na Lei SOX subdivide-se em diversas seções. Na lei destacam-se principalmente duas seções específicas em relação à Contabilidade: a Seção 302, pertencente ao Título III - Responsabilidade corporativa - e a Seção 404, contida no Título IV - Aumento do nível das divulgações financeiras. A primeira refere-se à declaração pessoal dos diretores executivos e diretores financeiros quanto à responsabilidade pelos controles e procedimentos de divulgação. Já a segunda, a Seção 404, determina a revisão dos controles e procedimentos internos para a emissão dos relatórios contábeis" (CUNHA; SILVA; FERNANDES, 2013, p.40).
} 
exigindo que a administração inclua em suas avaliações anuais um relatório específico sobre os controles internos" (SILVA; MACHADO, 2008, p.5).

No tocante à responsabilidade criminal e fraudes, deve-se destacar no tocante à SOX: penas de até dez anos de prisão em razão de adulteração ou destruição de registros com intuito de confundir investigação federal ou que diga respeito à falência, sanções a auditores que não mantenham todos os documentos de sua responsabilidade e proteção dos denunciantes das ilegalidades empresariais (whistleblowers) (MENEZES, 2018, p.34).

Por derradeiro, não se olvide, ainda no plano internacional, a publicação de documentos decorrentes de organizações que buscam estabelecer práticas adequadas para fins de compliance, conforme narram Leal e Ritt (2014, p.55):

Em 2010 a OCDE desenvolveu um documento que é voltado a implementação de programas de integridades nas empresas visando à prevenção e detecção de casos de suborno transnacional, que se chama de Good Practice Guidance on Internal Controls, Ethics, and Compliance. Ele estabelece 12 boas práticas que as empresas devem considerar para assegurar que seus programas de integridade sejam implementados com o objetivo de prevenir e detectar, de forma efetiva, práticas de suborno.

E, ainda, a existência, desde 1934, do Securities Exchange Act norte-americano, da qual deriva a SEC Rule 10b-5, a qual proíbe qualquer ação ou omissão que resulte em fraude no mercado mobiliário ${ }^{7}$.

\section{A LEI ANTICORRUPÇÃO NO BRASIL}

A necessidade de atender a alguns compromissos internacionais de combate à corrupção, tais como a Convenção das Nações Unidas contra a Corrupção (Decreto 5.687/2006), a Convenção Interamericana de Combate à Corrupção (Decreto 4.410/2002) e a Convenção sobre o Combate da Corrupção de Funcionários Públicos Estrangeiros em Transações Comerciais Internacionais da Organização para a Cooperação e Desenvolvimento Econômico (Decreto 3.648/2000), bem como a equiparação a sistemas adotados no Reino Unido e nos Estados Unidos (RIBEIRO; DINIZ, 2015, p.98), deram ensejo ao Projeto de Lei 6.826/2000, convertido, após aprovado, na Lei 12.846/2013, conhecida como Lei Anticorrupção Empresarial. Ao depois, não se

\footnotetext{
7 "Rule 10b-5: Employment of Manipulative and Deceptive Practices. It shall be unlawful for any person, directly or indirectly, by the use of any means or instrumentality of interstate commerce, or of the mails or of any facility of any national securities exchange, (a) To employ any device, scheme, or artifice to defraud, (b) To make any untrue statement of a material fact or to omit to state a material fact necessary in order to make the statements made, in the light of the circumstances under which they were made, not misleading, or (c) To engage in any act, practice, or course of business which operates or would operate as a fraud or deceit upon any person, in connection with the purchase or sale of any security".
} 
despreze que as mobilizações de julho de 2013 e os eventos internacionais a serem realizados no país aceleraram o trâmite do projeto.

Nos termos do seu artigo $1^{\circ}$, a lei “dispõe sobre a responsabilização objetiva administrativa e civil de pessoas jurídicas pela prática de atos contra a administração pública, nacional ou estrangeira". Este, aliás, o foco da lei, diante da inexistência de uma regulamentação mais específica sobre a responsabilidade das empresas que pratiquem atos de corrupção e causem danos ao erário público.

O parágrafo único do referido artigo destaca que a lei se volta às sociedades, empresárias e simples, personificadas ou não, de qualquer modelo societário, e ainda fundações, associações ou pessoas ou sociedades estrangeiras com sede, filial ou representação no país.

Conforme destacam Ribeiro e Diniz (2015, p.99), “a responsabilização é objetiva em relação à pessoa jurídica, e subjetiva em relação aos dirigentes e administradores, sendo que uma não exclui a outra”. A responsabilidade objetiva, aspecto extremamente inovador, olha apenas para o resultado, ignorando qualquer dolo ou culpa por parte dos responsáveis.

(...) a chamada Lei Anticorrupção Empresarial estabelece que empresas, fundações e associações passarão a responder civil e administrativamente sempre que a ação de um empregado ou representante causar prejuízos ao patrimônio público, infringir princípios da administração pública ou compromissos internacionais assumidos pelo Brasil. É a chamada responsabilização objetiva, prevista nas esferas civil e administrativa (XAVIER et alli, 2017, p.4).

Ao depois, deve-se destacar a insuficiência da regulamentação dos ilícitos administrativos praticados pelas empresas até o advento da LAE, que se limitavam a aspectos da Lei de Licitação, como a declaração de inidoneidade. Era preciso ir além para alcançar a responsabilidade administrativa quando os atos praticados pelas empresas causarem lesão ao patrimônio público, violação dos princípios da administração e violação de compromissos internacionais (LEAL; RITT, 2014, p.51).

$\mathrm{O}$ artigo $5^{\circ}$ da lei faz referência a uma série de atos lesivos, assim considerados "todos aqueles praticados pelas pessoas jurídicas mencionadas no parágrafo único do art. 1o, que atentem contra o patrimônio público nacional ou estrangeiro, contra princípios da administração pública ou contra os compromissos internacionais assumidos pelo Brasil”. Incluem: I - prometer, oferecer ou dar, direta ou indiretamente, vantagem indevida a agente público, ou a terceira pessoa a ele relacionada; II - comprovadamente, financiar, custear, patrocinar ou de qualquer modo subvencionar a prática dos atos ilícitos previstos nesta Lei; III - comprovadamente, utilizar-se de interposta pessoa física ou jurídica para ocultar ou dissimular seus reais interesses ou a identidade dos beneficiários dos atos praticados; IV - no tocante a licitações e contratos: a) frustrar ou fraudar, 
mediante ajuste, combinação ou qualquer outro expediente, o caráter competitivo de procedimento licitatório público; b) impedir, perturbar ou fraudar a realização de qualquer ato de procedimento licitatório público; c) afastar ou procurar afastar licitante, por meio de fraude ou oferecimento de vantagem de qualquer tipo; d) fraudar licitação pública ou contrato dela decorrente; e) criar, de modo fraudulento ou irregular, pessoa jurídica para participar de licitação pública ou celebrar contrato administrativo; f) obter vantagem ou benefício indevido, de modo fraudulento, de modificações ou prorrogações de contratos celebrados com a administração pública, sem autorização em lei, no ato convocatório da licitação pública ou nos respectivos instrumentos contratuais; ou g) manipular ou fraudar o equilíbrio econômico-financeiro dos contratos celebrados com a administração pública; V - dificultar atividade de investigação ou fiscalização de órgãos, entidades ou agentes públicos, ou intervir em sua atuação, inclusive no âmbito das agências reguladoras e dos órgãos de fiscalização do sistema financeiro nacional ${ }^{8}$.

$\mathrm{Na}$ esfera administrativa, as pessoas jurídicas praticantes de tais atos sofrerão as seguintes sanções $\left(\operatorname{art.} 6^{\circ}\right.$ ): I - multa, no valor de 0,1\% (um décimo por cento) a 20\% (vinte por cento) do faturamento bruto do último exercício anterior ao da instauração do processo administrativo, excluídos os tributos, a qual nunca será inferior à vantagem auferida, quando for possível sua estimação ${ }^{9}$; e II - publicação extraordinária da decisão condenatória.

A aplicação das sanções poderá ser conjunta ou isolada, de acordo com a gravidade e natureza das infrações e as peculiaridades do caso concreto. Ademais, mesmo a sanção econômica não exclui a necessidade de reparação do dano causado.

De forma muito próxima da Lei do CADE, na aplicação das sanções serão considerados os seguintes elementos: I - a gravidade da infração; II - a vantagem auferida ou pretendida pelo infrator; III - a consumação ou não da infração; IV - o grau de lesão ou perigo de lesão; V - o efeito negativo produzido pela infração; VI - a situação econômica do infrator; VII - a cooperação da pessoa jurídica para a apuração das infrações; VIII - a existência de mecanismos e procedimentos internos de integridade, auditoria e incentivo à denúncia de irregularidades e a aplicação efetiva de códigos de ética e de conduta no âmbito da pessoa jurídica; IX - o valor dos contratos mantidos pela pessoa jurídica com o órgão ou entidade pública lesados ${ }^{10}$.

\footnotetext{
8 "Os ilícitos arrolados ao longo dos incisos do artigo $5^{\circ}$ da Lei 12.846/13 e que podem configurar atos de corrupção são: obtenção de vantagem indevidas (incisos I, II, III) e a prática de condutas antijurídicas em licitações (incisos IV) e obstrução das investigações (V). Tais condutas são infrações administrativas, ou seja, o descumprimento voluntário de uma norma para a qual se prevê sanção não restritiva de liberdade, cuja imposição cabe a uma autoridade no exercício de uma função administrativa” (KEMPFER; BATISTI, 2017, p.294).

${ }^{9}$ Se não for possível utilizar o critério de faturamento bruto da pessoa jurídica, a multa será fixada em valor entre $\mathrm{R} \$$ $6.000,00$ (seis mil reais) e $\mathrm{R} \$ 60.000 .000,00$ (sessenta milhões de reais). Os valores a serem tomados por base quanto ao faturamento levarão em conta o exercício antecedente ao processo administrativo de responsabilização (PAR).

10 "Contudo, a carência de regulamentação em relação à dosimetria da pena, além da ausência de objetividade em relação aos reais benefícios a serem concedidos às empresas que tiverem política de Compliance efetivo, podem fazer
} 
O objetivo da lei, contudo, além de desestimular as práticas corruptivas é estimular, por meio de redução das penalidades aplicadas, a adoção de programas de compliance (XAVIER et alli, 2017, p.4). Daí o inciso VIII do artigo $7^{\circ}$ acima mencionado. A propósito, nos termos do parágrafo único do mesmo dispositivo os parâmetros para avaliação do programa devem constar de decreto, no caso o Decreto 8.420/2015, que regulamenta a LAE.

Tais parâmetros constam do artigo 41 e seguintes do referido Decreto, mais especificamente nos termos do artigo 42 , com destaque para os itens que indicam, justamente, as bases de qualquer programa de compliance: I - comprometimento da alta direção da pessoa jurídica, incluídos os conselhos, evidenciado pelo apoio visível e inequívoco ao programa; II - padrões de conduta, código de ética, políticas e procedimentos de integridade, aplicáveis a todos os empregados e administradores, independentemente de cargo ou função exercidos; III - padrões de conduta, código de ética e políticas de integridade estendidas, quando necessário, a terceiros, tais como, fornecedores, prestadores de serviço, agentes intermediários e associados; IV - treinamentos periódicos sobre o programa de integridade; V - análise periódica de riscos para realizar adaptações necessárias ao programa de integridade; VI - registros contábeis que reflitam de forma completa e precisa as transações da pessoa jurídica; VII - controles internos que assegurem a pronta elaboração e confiabilidade de relatórios e demonstrações financeiros da pessoa jurídica; VIII - procedimentos específicos para prevenir fraudes e ilícitos no âmbito de processos licitatórios, na execução de contratos administrativos ou em qualquer interação com o setor público, ainda que intermediada por terceiros, tal como pagamento de tributos, sujeição a fiscalizações, ou obtenção de autorizações, licenças, permissões e certidões; IX - independência, estrutura e autoridade da instância interna responsável pela aplicação do programa de integridade e fiscalização de seu cumprimento; X - canais de denúncia de irregularidades, abertos e amplamente divulgados a funcionários e terceiros, e de mecanismos destinados à proteção de denunciantes de boa-fé; XI medidas disciplinares em caso de violação do programa de integridade; XII - procedimentos que assegurem a pronta interrupção de irregularidades ou infrações detectadas e a tempestiva remediação dos danos gerados; XIII - diligências apropriadas para contratação e, conforme o caso, supervisão, de terceiros, tais como, fornecedores, prestadores de serviço, agentes intermediários e associados; XIV - verificação, durante os processos de fusões, aquisições e reestruturações societárias, do cometimento de irregularidades ou ilícitos ou da existência de vulnerabilidades nas pessoas jurídicas envolvidas; XV - monitoramento contínuo do programa de integridade visando seu aperfeiçoamento na prevenção, detecção e combate à ocorrência dos atos lesivos previstos no

com que a referida Lei Anticorrupção brasileira não seja concebida como uma verdadeira estrutura de incentivos, pois não demonstra claramente que os benefícios advindos de sua implantação serão maiores que os prejuízos em caso da não implantação” (RIBEIRO; DINIZ, 2015, p.102). 
art. $5^{\circ}$ da Lei n 12.846 , de 2013 ; e XVI - transparência da pessoa jurídica quanto a doações para candidatos e partidos políticos.

Ademais, conforme $\$ 1^{\circ}$ do mesmo dispositivo, para avaliar os parâmetros acima devem ser considerados o porte e especificidades da pessoa jurídica, incluindo: I - a quantidade de funcionários, empregados e colaboradores; II - a complexidade da hierarquia interna e a quantidade de departamentos, diretorias ou setores; III - a utilização de agentes intermediários como consultores ou representantes comerciais; IV - o setor do mercado em que atua; V - os países em que atua, direta ou indiretamente; VI - o grau de interação com o setor público e a importância de autorizações, licenças e permissões governamentais em suas operações; VII - a quantidade e a localização das pessoas jurídicas que integram o grupo econômico; e VIII - o fato de ser qualificada como microempresa ou empresa de pequeno porte.

Daí a razão pela qual Kempfer e Batisti (2017, p.293) asseverarem que a lei possui dois direcionamentos no combate à corrupção, um repressivo e um preventivo. O repressivo estaria ínsito à responsabilidade objetiva das empresas e às sanções aplicadas. Já o aspecto preventivo estaria disposto no apelo aos programas de integridade e nos acordos de leniência.

Quanto a estes, a propósito, cumpre frisar o estabelecimento de um ajuste entre a empresa causadora da ilicitude e o Estado sancionador. Pela medida, ao receber a notícia e esclarecimentos da organização confessa, o Estado aplica sua sanção, mas com uma premiação em razão da assunção do erro.

\footnotetext{
Para que o acordo de leniência se consume, é preciso que as partes envolvidas percebam vantagens nas tratativas. Para o Estado, indispensável que sejam alcançados alguns resultados como a descoberta dos demais envolvidos na infração, quando couber; obtenção célere de informações e documentos que comprovem o ilícito sob apuração. Já para a empresa, os benefícios consistem basicamente na redução das sanções (KEMPFER; BATISTI, 2017, p.297).
}

Consoante disposto no artigo 16 da LAE, a autoridade máxima de cada órgão ou entidade pública poderá celebrar o referido acordo, desde que, da colaboração, resulte identificação dos demais envolvidos, quando for o caso, e a obtenção célere de informações e documentos que comprovem o ilícito sob apuração.

Além disso, é preciso que sejam preenchidos, cumulativamente, os requisitos: I - a pessoa jurídica seja a primeira a se manifestar sobre seu interesse em cooperar para a apuração do ato ilícito; II - a pessoa jurídica cesse completamente seu envolvimento na infração investigada a partir da data de propositura do acordo; III - a pessoa jurídica admita sua participação no ilícito e coopere plena e permanentemente com as investigações e o processo administrativo, comparecendo, sob suas expensas, sempre que solicitada, a todos os atos processuais, até seu encerramento. 
No tocante às cláusulas do acordo, deverá haver compromisso de cumprimento dos requisitos dispostos nos incisos II a V do artigo 30 do Decreto (ter cessado completamente seu envolvimento no ato lesivo a partir da data da propositura do acordo; admitir sua participação na infração administrativa; cooperar plena e permanentemente com as investigações e o processo administrativo e comparecer, sob suas expensas e sempre que solicitada, aos atos processuais, até o seu encerramento; e fornecer informações, documentos e elementos que comprovem a infração administrativa), a perda dos benefícios pactuados caso o acordo seja descumprido, a natureza de título extrajudicial do acordo e a adoção, aplicação ou aperfeiçoamento do programa de integridade.

Em caso de aceitação, os efeitos abarcarão a isenção de publicação da decisão condenatória e da proibição de receber incentivos, subsídios, subvenções, doações ou empréstimos de órgãos ou entidades públicas e de instituições financeiras públicas ou controladas pelo poder público, pelo prazo mínimo de 1 (um) e máximo de 5 (cinco) anos, e, ainda, redução em até dois terços (2/3) da multa aplicável.

Ainda na esfera administrativa federal, a lei estabelece a criação do Cadastro Nacional de Empresas Punidas - CNEP, que, conforme artigo 22, "reunirá e dará publicidade às sanções aplicadas pelos órgãos ou entidades dos Poderes Executivo, Legislativo e Judiciário de todas as esferas do governo".

O Decreto 8.420, além do CNEP, busca amparo no Cadastro Nacional de Empresas Inidôneas e Suspensas - CEIS, previsto na Lei de Licitação, a fim de dar ampla publicidade acerca de suspensões, inidoneidades e impedimentos de contratar com a Administração Pública (art. 43).

Além das vertentes administrativas, existem ainda sanções judiciais, estipuladas no artigo 19 da LAE, e independente da esfera administrativa. Assim estabelece referido dispositivo:

Art. 19. Em razão da prática de atos previstos no art. 5o desta Lei, a União, os Estados, o Distrito Federal e os Municípios, por meio das respectivas Advocacias Públicas ou órgãos de representação judicial, ou equivalentes, e o Ministério Público, poderão ajuizar ação com vistas à aplicação das seguintes sanções às pessoas jurídicas infratoras:

I - perdimento dos bens, direitos ou valores que representem vantagem ou proveito direta ou indiretamente obtidos da infração, ressalvado o direito do lesado ou de terceiro de boa-fé;

II - suspensão ou interdição parcial de suas atividades;

III - dissolução compulsória da pessoa jurídica;

IV - proibição de receber incentivos, subsídios, subvenções, doações ou empréstimos de órgãos ou entidades públicas e de instituições financeiras públicas ou controladas pelo poder público, pelo prazo mínimo de 1 (um) e máximo de 5 (cinco) anos.

$\int 1$ o A dissolução compulsória da pessoa jurídica será determinada quando comprovado: I - ter sido a personalidade jurídica utilizada de forma habitual para facilitar ou promover a prática de atos ilícitos; ou

II - ter sido constituída para ocultar ou dissimular interesses ilícitos ou a identidade dos beneficiários dos atos praticados.

$\int 20$ (VETADO).

$\int 30$ As sanções poderão ser aplicadas de forma isolada ou cumulativa. 
\40 O Ministério Público ou a Advocacia Pública ou órgão de representação judicial, ou equivalente, do ente público poderá requerer a indisponibilidade de bens, direitos ou valores necessários à garantia do pagamento da multa ou da reparação integral do dano causado, conforme previsto no art. 7o, ressalvado o direito do terceiro de boa-fé.

Se a ação for ajuizada pelo Ministério Público e ter ocorrido omissão quanto às sanções administrativas, poderá a ação judicial aplicar, ainda, as sanções previstas no artigo $6^{\circ}$ da lei.

Não se olvide, por derradeiro, que, do outro lado, o Estatuto das Empresas Estatais (Lei 13.300/2016) estabelece que as empresas públicas e as sociedades de economia mista também deverão adotar programas de integridade, código de conduta e comitê de auditoria, no intuito de lidar com a gestão de risco. Trata-se do programa de compliance público (COELHO, 2016, p.85 e ss).

\section{CONCLUSÃO}

Mais do que uma postura de repressão aos atos corruptivos, a legislação nacional e internacional passou a estimular, nos últimos anos, a adoção de programas de integridade, consubstanciado em instrumentos que permitem asseverar a conformidade legal das empresas e a postura ética perante a Administração Pública.

O compliance - também conhecido por "programa de integridade" - revela uma posição de anteparo ao risco, identificando-o e construindo condutas dialéticas, claras e difundidas para lidar com as possíveis desconformidade decorrentes da inserção do mercado, decorrentes da própria posição empresarial ou de seu relacionamento com outros agentes públicos ou privados.

O Foreign Corrupt Practices Act norte-americano, ao inovar a temática, ainda em 1977, passou a sancionar as empresas norte-americanas que se valessem de práticas de facilitação e outras demandas corruptivas no exterior, revelando uma preocupação com a postura ética mesmo fora do seu território.

Em 2002, em decorrência de escândalos ocorridos no mercado financeiro, a Lei SarbanesOxley passou a conter exigências inéditas, em especial quanto a uma auditoria realmente independente, das empresas que negociassem valores mobiliários nos Estados Unidos. Num primeiro momento, a SOX afetou a conduta de diversas empresas brasileiras que negociavam ações na Bolsa de Nova York. Num segundo, influenciou a adoção, por parte de empresas ao redor do mundo, de práticas que garantissem conformidade legal e integridade de suas informações.

Entre nós, o Projeto de Lei 6.826/2000 veio a gerar a Lei 12.846/2013, conhecida por Lei Anticorrupção. Peculiar em relação à legislação anterior, a LAE teve o propósito de punir 
objetivamente as pessoas jurídicas que praticassem ilícitos que trouxessem prejuízo ao erário público, na esfera administrativa e na esfera judicial.

Mas não apenas. Cuidou, sob a égide preventiva, de estimular a criação de programas de compliance, consoante as diretrizes estabelecidas no Decreto 8.420/2015. Mais do que isso, a lei estipulou que a adoção de programas de integridade atuaria como uma espécie de atenuante diante de inevitável conduta de desconformidade. Estipulou, ainda, que a sua existência ou futura existência influenciaria nos acordos de leniência eventualmente realizados.

Trouxe a lei, ainda, outros instrumentos de desestímulo às práticas corruptivas. E, especialmente, traçou uma nova diretriz no contexto da relação público-privada brasileira. Daí decorrente, por exemplo, a transposição do compliance para as empresas estatais, nos termos da Lei $13.300 / 2016$.

A tendência brasileira, na esteira global, é de uma avaliação progressivamente positiva das empresas que adotam tais programas, mormente quanto realmente eficazes. Novas medidas advirão e passarão a dominar o cenário jurídico brasileiro. E, assim o seja, para que o futuro se desvie das desconformidades do passado.

\section{REFERÊNCIAS}

BIELGELMAN, Martin T. Building a world-class compliance program. Hoboken: John Wiley, 2008.

CASTRO, Patrícia Reis; AMARAL, Juliana Ventura; GUERREIRO, Reinaldo. Aderência ao programa de integridade da lei anticorrupção brasileira e implantação de controles internos. Revista Contabilidade \& Finanças, v.30, n.80, mai./ago. 2019, p.186-201.

COELHO, Cláudio Carneiro Bezerra Pinto. Compliance na Administração Pública: uma necessidade para o Brasil. Revista de Direito da Faculdade Guanambi, v.3, n.1, jul./dez. 2016, p.75-95.

CONSELHO ADMINISTRATIVO DE DEFESA ECONÔMICA. Guia Programas de Compliance: orientações sobre estruturação e benefícios da adoção dos programas de compliance concorrencial. Brasília: Ministério da Justiça, 2016.

CONTROLADORIA-GERAL DA UNIÃO. Programa de integridade: diretrizes para empresas privadas. Brasília: CGU, 2015.

CUNHA, Paulo Roberto da; SILVA, Júlio Orestes da; FERNANDES, Francisco Carlos. Pesquisas sobre a lei Sarbanes-Oxley: uma análise dos journals em língua inglesa. Reflexão contábil, v.32, n.2, mai./ago. 2013, p.37-51.

IBDEE. Código de compliance corporativo: guia de melhores práticas de compliance no âmbito empresarial. São Paulo: Instituto Brasileiro de Direito e Ética Empresarial, 2017. 
KEMPFER, Marlene; BATISTI, Beatriz Miranda. Estudos sobre o compliance para prevenção da corrupção nos negócios públicos: ética, ciência da administração e direito. Revista do Direito Público, v.12, n.2, ago.2017, p.273-307.

LEAL, Rogério Gesta; RIT'T, Caroline Fockink. A previsão dos mecanismos e procedimentos internos de integridade: compliance corporativo na Lei Anticorrupção: sua importância considerado como uma mudança de paradigmas e educação empresarial. Barbarói, n.42, jul./dez. 2014, p.43-63.

MENDES, Francisco Schertel; CARVALHO, Vinicius Marques de. Compliance: concorrência e combate à corrupção. São Paulo: Trevisan, 2017.

MENEZES, Guilherme Alves. A influência da lei Sarbanes-Oxley (SOX) nas normas e regras nacionais da governança corporativa no setor de telecomunicações do Brasil. Dissertação de Mestrado. Universidade Federal do Paraná, Programa de Pós-Graduação em Contabilidade, Curitiba, 2018, 128p.

PATRIA. Manual de Compliance. São Paulo: Pátria Investments, 2017, p.1.

PETROBRAS. Programa Petrobras de prevenção da corrupção. Rio de Janeiro: Petróleo Brasileiro S.A., 2015.

RIBEIRO, Marcia Carla Pereira; DINIZ, Patrícia Dittrich Ferreira. Compliance e Lei Anticorrupção nas empresas. Revista de Informação Legislativa, a.52, n. 205, jan./mar. 2015, p.87105.

SILVA, Letícia Medeiros da; MACHADO, Silvana de Borba Zorn. Um estudo sobre a Lei Sarbanes-Oxley na área de auditoria interna de uma empresa brasileira com ações negociadas nos Estados Unidos. Anais do $18^{\circ}$ Congresso Brasileiro de Contabilidade. Gramado, 2008.

VERÍSSIMO, Carla. Compliance: incentivo à adoção de medidas anticorrupção. São Paulo: Saraiva, 2017.

VIEIRA, Mariana Pessoa. Compliance: ferramenta estratégica para as boas práticas de gestão. Trabalho de conclusão de curso. Bacharelado em Secretariado Executivo Trílingue, Universidade Federal de Viçosa, Viçosa, 2013. 60f.

XAVIER, Deiverson Felipe Souza; COSTA, Dáphine Pereira; ALMEIDA, Luiz Osvaldo Vilar de; SOARES, Lucas Beraldo. Compliance: uma ferramenta estratégica para a segurança das informações nas organizações. Anais do VI Simpósio Internacional de Gestão de Projetos, Inovação e Sustentabilidade, São Paulo, 2017. 